\title{
Poesia na infância e formação de leitores
}

\author{
Fernando José Fraga de Azevedo* \\ Isabel Souto e Melo*
}

\section{Resumo}

Este artigo apresenta um conjunto de estratégias para ler e apreciar a poesia em contexto escolar, particularmente nos primeiros anos da escolaridade. A poesia é concebida como um tipo de texto onde a elevada concentração sígnica e a multivalência semântica, expandidas pela plurissignificaçáo da conjugação dos elementos do conteúdo com os da expressão, possibilita, ao leitor, o contato emocional e afetivo com o estado de coisas do mundo empírico e histórico-factual, sugerindo percursos hermenêuticos plurais para o seu acesso, conhecimento e reflexão. Assume-se, ao longo do texto, que a fruição do texto poético é relevante na criação de hábitos leitores, aspeto crucial para a formação de leitores capazes de ler voluntariamente em quantidade e em qualidade. Palavras-chave: Literatura infantil. Leitura. Didática.

* Doutorado em Ciências da Literatura, área do conhecimento de Literatura Portuguesa, pela Universidade do Minho. Professor Associado com Agregaçáo do Instituto de Educação na Universidade do Minho. É regente das unidades curriculares de Literatura para a Infância e Juventude, assim como de Literacia e Mediação Leitora, nos cursos de Licenciatura e de Pós-Graduação do Instituto de Educaçáa. Membro do Centro de Investigação em Estudos da Criança.

** Doutorado em Estudos da Criança, área do conhecimento de Literatura para a Infância, pela Universidade do Minho - Portugal, e membro do Centro de Investigaçáo em Estudos da Criança do Instituto de Educação na mesma universidade. 
Formar leitores, capazes de ler voluntariamente, com qualidade e sofisticação, constitui atualmente um dos maiores desafios com que se confrontam as sociedades desenvolvidas. Se no passado o objetivo era primordialmente o de elevar o número de pessoas alfabetizadas, buscando proporcionar a todos os cidadãos o acesso à cultura escrita e aos mundos que ela irradia, hoje, trata-se de garantir que o cidadão é não só capaz de ler e de interpretar qualquer texto, como é capaz de o fazer de forma não ingénua, ultrapassando a estrutura de superfície do texto e alcançando a sua matriz profunda. De fato, reconhecendo produtivamente, entre outros aspetos, os mecanismos de disposição estratégica da informaçáo, geradores, junto dos potenciais destinatários, de determinados efeitos perlocutivos, o leitor competente mostra-se capaz de ler criticamente os textos na pluralidade das suas funçôes, incluindo também a ideológica (FREIRE, 1987). Ora ler, nesta perspetiva, implica interpretar e compreender o texto, ser capaz de realizar inferências, conectando o mundo textual com os mundos extratextuais (MARCUSCHI, 1995; FILLOLA, 2003; FERREIRA; DIAS, 2004; SPINILLO; MAHON, 2007).

Alcançar o objetivo de formar bons leitores, leitores competentes e sofisticados, leitores que leem em qualidade e em quantidade numa pluralidade de contextos e com interesses diversificados não constitui tarefa fácil.

Se é verdade que não nascemos leitores, também é verdade que, como sublinhou Pedro Cerrillo (2006), não nascemos não leitores. $\mathrm{O}$ assumirmos a leitura como projeto pessoal e o manifestarmos esse comportamento depende, entre outros aspetos, das experiências positivas que tivemos ao longo dos nossos percursos de vida, assim como também dos contextos e dos objetivos que presidem à exercitação dessa atividade. A perspetiva da leitura voluntária é, de fato, uma atividade que envolve paixão, entusiasmo, prazer, atos esses que José Antonio Marina e María de la Válgoma (2007, p. 73-74) discriminam como receitas mágicas para a motivação:

Primeira receita mágica: Contagiar os nossos entusiasmos por meio de uma poética apaixonada e tenaz;

Segunda receita mágica: Aproveitar a tendência que têm os seres humanos para imitar as condutas que veem, e em especial as pessoas de quem gostam, admiram ou pelas quais desejam ser aceites;

Terceira receita mágica: Usar o estabelecimento de metas e recompensas. Os seres humanos tendem a repetir os 
comportamentos que são premiados. As recompensas têm que ver com os grandes anseios e necessidades das pessoas, sentir-se queridas, progredir, ampliar as próprias possibilidades, ser aceites pelo seu grupo;

Quarta receita mágica: Fomentar a aquisição de hábitos, que são grandes provocadores de desejos. Graças a eles podemos educar as nossas preferências;

Quinta receita mágica: Mudar o sistema de convicçóes acerca de uma atividade.

No entender de José Antonio Marina e María de la Válgoma (2007, p. 67), "o desejo de fazer qualquer coisa depende do atrativo que essa ação revele", o que no processo da leitura é crucial porque a leitura deve ter um caráter significativo, algo que a ligue aos objetivos pessoais do leitor e que tenha um cunho desafiante, diversificado e seja detentora, simultaneamente, de novidade semiótica, numa interação entre "afeto, atitude e motivação" (GUTHRIE; MCCANN, 1997; SOLÉ, 2000; BÁRTOLO, 2004), numa continuidade de processos que envolva o prazer e a satisfação pessoal.

Este artigo procurará apresentar estratégias que, potenciando uma relação afetiva da criança com o texto literário, possam contribuir precocemente para a aquisição e desenvolvimento, por parte desta, de uma competência literária, aspeto essencial, como demonstrámos noutro lugar (AZEVEDO, 2011), para a sua capacidade de ler o mundo de uma forma sofisticada. $O$ género textual escolhido é a poesia, um tipo de texto onde a concentração sígnica e a multivalência semântica, expandidas pela plurissignificação da conjugação dos elementos do conteúdo com os da expressáo, possibilita, ao leitor, o contato emocional e afetivo com o estado de coisas do mundo empírico e históricofactual, sugerindo veredas plurais para o seu acesso, conhecimento e reflexáo.

A linguagem da literatura, como sublinhou Bernice Cullinan (2003, p. 20), "atrae la atención y provoca que el lector haga una pausa para pensar no solo en lo que se está diciendo, sino en cómo se está diciendo". Neste sentido, o contato frequente com a literatura leva a que as crianças interiorizem os modelos retóricos e passem também a utilizá-los nas suas próprias criaçóes. Além disso, a análise deste tipo de textos ajuda os jovens leitores a tornaremse leitores críticos e seletivos, ou seja, a desenvolverem a sua competência literária. Assim, a introdução precoce destes textos nas escolas facilita não só a 
aprendizagem do vocabulário necessário à comunicação verbal, como também promove a sua ampliação.

Na mesma linha de pesquisa, Hallie e Ruth Yopp (2006) desenvolveram um conjunto de atividades de leitura baseadas na literatura que, na sua globalidade, enfatizam o papel do leitor enquanto co-construtor dos significados textuais: atividades de pré-leitura, que permitem ativar determinados horizontes de expetativa, antecipar informação e suscitar a curiosidade perante o texto; atividades de leitura, que possibilitam construir significados, motivando respostas pessoais; e atividades de pós-leitura, que buscam integrar e sistematizar conhecimentos.

Barbara Chatton (1993) considera que é importante garantir na escola um ambiente que origine a partilha entre alunos, entre alunos e professores e entre a escola e a comunidade educativa, de textos poéticos, seja através da vivência de cada um na leitura, seja através da recitação ou da dramatização.

Entre a rede de possibilidades poéticas apresentadas pela autora no seu livro Using Poetry across the Curriculum, para cada uma das macro-capacidades (ler, escrever, falar e ouvir), destacamos as atividades propostas para a competência do modo oral (CHATTON, 1993), que, ao tornarem-se rotinas em sala de aula, ajudam a promover o desejado ambiente de partilha impulsionador da poesia. Desde ler ou recitar um poema para os colegas, fazer gravaçóes com recitação de poesia, discutir as ideias e as emoçóes de cada um face a um determinado poema, partilhar a afetividade do significado de poemas recitados em sala de aula, apresentar aos colegas novos versos criados para poemas ou cançóes, ouvir o professor ou os animadores de bibliotecas a recitarem poesia, ouvir os colegas a recitarem os seus poemas preferidos, ouvir gravaçōes com declamaçóes de poesia ou ouvir poetas a falarem sobre os seus textos, todas estas atividades constituem um bom ponto de partida para a abordagem poética.

Partilhando a mesma filosofia, Aaren Yeatts Perry (1997) apresenta, na obra Poetry across the Curriculum, várias razóes para que a poesia suporte a aprendizagem das mais variadas áreas curriculares. A autora defende que a partilha de novos conteúdos pode ser feita de uma forma criativa e com muito mais interesse para alunos e professor se se recorrer à poesia em sala de aula:

Studying the poem itself requires and encourages a range of academic skills. It calls for basic listening and reading skills. Poetry study trains one in many modes of thinking: 
nonlinear, freethinking; sequential, ordered, critical, and scientific thinking; musical and rhythmic thinking; and philosophical thinking. Poetry also demands the ability to stop thinking, remain quiet, and receive information through other channels. (PERRY, 1997, p. xv).

Desta forma, pode considerar-se Poetry across the Curriculum (PERRY, 1997) como um guia para professores do ensino elementar, repleto de sugestôes de atividades de escrita poética, com planos de aula e os respetivos passos sequenciais. Embora as propostas se centrem em exercícios de escrita, certo é que encontramos nas suas planificaçóes o equilíbrio entre as macro-competências, incluindo o funcionamento da língua. A estrutura e a organização das atividades seguem algumas metodologias de forma constante: um primeiro momento, o warm up, com atividades de expressão oral quer seja a falar ou a ouvir; o desenvolvimento, num segundo momento, com atividades de escrita e leitura; e na consolidação, terceiro momento, novamente a leitura e a expressão oral, quer seja na partilha dos trabalhos quer seja na sua discussão e/ou avaliação.

Verifica-se pois que alguns professores e investigadores recorrem à poesia para pôr em prática a filosofia do programa correntemente designado como Whole Language Approach. E o mais curioso na abordagem de Perry (1997) é o facto de apresentar as suas atividades organizadas e distribuídas por capítulos correspondentes a áreas disciplinares ou conteúdos generalistas, divididos da seguinte forma: "Arte", "Língua Materna", "Saúde", "Música", "Ciências", "Estudos Sociais", "Valores Humanos" e "Cidadania". Esta distribuição não é estática, mas dinâmica, já que, em vários momentos, Perry propóe o cruzamento das várias áreas, assinalando "cross-curricula". Além disso, cada capítulo de Poetry across the Curriculum (PERRY, 1997) conta ainda com sugestôes metodológicas variadas para diferentes níveis de ensino.

Fred Sedgwick (2000) defende uma aprendizagem articulada da língua e da literatura, em particular do texto poético, já que ambas, língua e poesia, possibilitam aos alunos o conhecimento sobre si próprios, sobre o ambiente, sobre a relação entre os próprios e o ambiente e sobre a língua. As atividades apresentadas na sua obra Writing to Learn: Poetry and Literacy Across the Primary Curriculum (SEDGWICK, 2000) procuram mostrar que o poder da poesia se traduz na capacidade de as crianças aprenderem, sob uma perspetiva holística, a conhecer o mundo que as rodeia. 
Reclamando a essência da National Literacy Strategy, desenvolvida no Reino Unido, nos finais da década de 90, Sedgwick (2000) propóe que os professores tratem os seus alunos como aprendentes ativos, estimulando-os a trazerem para a sala de aula temáticas para serem trabalhadas através da poesia. Para este autor britânico (SEDGWICK, 2000, p. xviii), "poetry is more than something beautiful [...] It is a teacher or [...] a research tool [...] a way of learning, a way of knowing". Só desta forma, no seu entender, se pode vislumbrar o verdadeiro entendimento da palavra literacia: "poetry teaches children as children write it. It helps them to get the world right" (SEDGWICK, 2000, p. xviii).

Como havia salientado Northrop Frye (1963, p. 26), muitos anos antes, "Poetry [...] is always the central powerhouse of a literary education", já que só este género "can do something to develop a speaking and prose style that comes out of the depths of personality and is a genuine expression of it". No entanto, a poesia raramente é abordada em sala de aula com este mesmo objetivo, esquecendo-se os professores da natural propensão dos seus alunos para o poético e para as suas características potencializadoras da reflexáo e da expressão pessoal.

Em The Child as Critic. Teaching Literature in Elementary and Middle Schools, Glenna Davis Sloan (1991) defende a primazia da poesia num programa de leitura fundamentado na literatura, na medida em que o aspeto afetivo da linguagem, frequentemente negligenciado na educação formal, merece a seu ver ser devidamente abordado na sala de aula. É que, em termos de expressão, a criança aproxima-se muito naturalmente do poeta: "children are explorers of language" (SLOAN, 1991, p. 94). O poeta, tal como a criança, vê-se maravilhado com tudo aquilo que pode fazer com as palavras, utilizando para o efeito técnicas e recursos retórico-discursivos, como a rima, a aliteração e a onomatopeia, que são elementos naturais na enunciação dos mais novos (SLOAN, 1991).

Segundo Fernando Gómez Martín (1993), as estratégias de motivação para a leitura do texto poético podem distribuir-se em vários momentos de aprendizagem que, de uma forma gradativa, promovem a aproximação das crianças e dos jovens à poesia.

Se é verdade que os professores e os educadores devem utilizar os melhores textos poéticos, imagísticos, rítmicos, com metáforas e imagens fortes e sensoriais, repetição e rima, Glenna Davis Sloan (1991) não deixa de enfatizar 
que esses textos devem igualmente ser adequados ao nível de compreensão dos seus leitores, permitindo ampliar a sua imaginação com novas maneiras de ver o mundo e pô-los em contacto com novas e interessantes aptidóes vocabulares. Sloan (1991, p. 99) acredita que "choosing poetry to use with children can never become an academic exercise", já que, acima de tudo, esta escolha tem de ser feita privilegiando-se o lado afetivo, independentemente do tema, de serem poemas clássicos ou contemporâneos, narrativos ou líricos.

Outros investigadores, como Brod Bagert (apud CULLINAN, 1992), concluíram nos seus estudos que os jovens leitores preferem poemas com humor e que contêm histórias. Bagert (apud CULLINAN, 1992, p. 16) apresenta mesmo uma fórmula para se selecionarem poemas para crianças, que consiste em Sound + Story + Character $=$ Fun , sublinhando que o primeiro passo para a escolha de poemas é que estes sejam fáceis de dramatizar e que entretenham uma audiência infantil. Segundo o autor, as crianças gostam de poemas cujos sons sejam divertidos para pronunciar, que contem uma história completa e que expressem a voz de alguém com quem se identifiquem.

Também Teresa Rita Lopes, na composição intitulada Palavras poucas (apud FANHA, 2005, p. 52), define os gostos das crianças relativamente à poesia:

\begin{tabular}{|c|c|}
\hline \multicolumn{2}{|l|}{$\begin{array}{l}\text { Dêem-me } \\
\text { um poema } \\
\text { de poucas } \\
\text { palavras! }\end{array}$} \\
\hline & $\begin{array}{l}\text { Gosto } \\
\text { de flores } \\
\text { com poucas } \\
\text { pétalas }\end{array}$ \\
\hline \multirow[t]{2}{*}{$\begin{array}{l}\text { do sabor } \\
\text { simples } \\
\text { do pão }\end{array}$} & \\
\hline & $\begin{array}{l}\text { de uma pedra } \\
\text { na palma } \\
\text { da mão }\end{array}$ \\
\hline
\end{tabular}


Neste poema, composto por estrofes irregularmente colocadas na página, o poema de poucas palavras é comparado às "flores com poucas pétalas", ao "sabor simples do pão" ou ao que sentimos com uma "pedra na palma da mão". Por um lado, poder-se-ão estender estas metáforas aos gostos simples das crianças, gostos ligados às sensaçóes físicas e aos prazeres quotidianos, expostos em poucas palavras e de uma forma livre na página. Por outro lado, o próprio poema, em poucas palavras, mostra como, na poesia em geral, não é a quantidade de palavras nem o conteúdo rebuscado que definem um bom texto. O essencial reside na singularidade do olhar, na limpidez daquilo que se mostra e daquilo que se expressa.

Cullinan, Scala e Schroder (1995, p. 6-7) apontam alguns critérios para a preferência infantil e entre eles destacamos os seguintes: poemas que façam os alunos experienciar emoçóes; poemas que os ajudem a criar imagens visuais, tácteis, olfativas ou de paladar; poemas que mostrem como é possível brincar/jogar com a linguagem; poemas que façam com que os alunos pensem no mundo de uma maneira alternativa. Na verdade, a poesia reflete, de modo não explícito, o que se passa no dia-a-dia; logo, tanto professores como alunos, de forma alternada, podem apresentar ao grupo um poema por dia, por eles selecionado, relacionado com situaçốes vivenciadas da sala de aula, de casa ou com os amigos.

Trabalhar a poesia em contexto pedagógico significa, pois, olhá-la como lugar para revisitar e recriar textos já conhecidos do património da tradição oral, expandindo e fertilizando saberes sedimentados pelo tempo, experimentar a emancipação da linguagem, jogando com os usos lúdicos e criativos da língua, e cruzar esta forma de expressão com outras formas de expressão artística como a música, a imagem ou a ilustração.

\section{Modelos ou formas poéticas da literatura de tradição oral}

Se antes da sua entrada para a escola a criança já mantém, no seio familiar, um contato muito próximo e afetivo com a poesia - recordemos que é comum a sua exposição a canções de embalar, lengalengas, quadras populares, cantigas ou refróes -, importa, em contexto pedagógico, dar continuidade a essa "relaçâo lúdica e exploratória com a língua" (BASTOS, 1999, p. 182), dado que as produçóes do património oral proporcionam, como enfatiza Fernando Gómez Martín (1993), atividades lúdicas e momentos de descontração, ao 
mesmo tempo que promovem o gosto dos mais pequenos pela cultura e folclore nacional.

A composição $A$ viagem, de António Mota, incluída em Se tu visses o que eu vi (MOTA, 2002, p. 30), por exemplo, promove estimulantes jogos sonoros, à boa maneira das lengalengas. A estrutura principal repete-se a cada nova estrofe ("Fui a... / a cavalo num..."), mudando a localidade ("Viana", "Funchal", etc.) e a forma ("numa cana", "num burro morto", etc.), que tem de rimar com a cidade enunciada:

$\begin{array}{ll}\begin{array}{l}\text { Fui a Viana } \\ \text { a cavalo numa cana. }\end{array} & \begin{array}{l}\text { Fui a Lisboa } \\ \text { a cavalo numa leoa. }\end{array} \\ \begin{array}{l}\text { Fui ao Porto } \\ \text { a cavalo num burro morto. }\end{array} & \begin{array}{l}\text { Fui ao Funchal } \\ \text { a cavalo num pardal. }\end{array} \\ \text { Fui a Braga } & \text { Fui ao Fundão } \\ \text { a cavalo numa cabra. } & \text { a cavalo num sardão. } \\ \text { Fui a Loulé } & \text { Fui a Lousada } \\ \text { a cavalo num chimpazé. } & \text { a cavalo numa pescada. } \\ \text { Fui a Caminha } & \text { Fui a Lamego } \\ \text { a cavalo numa galinha. } & \text { a cavalo num morcego. } \\ \text { Fui a Mirandela } & \text { Quando a viagem terminou } \\ \text { a cavalo numa cadela. } & \text { o meu sonho acabou. }\end{array}$

Os jogos verbais presentes nesta composição, além de proporcionarem uma aprazível iniciação à produção de rimas (Caminha/galinha, Lamego/ morcego) promovem a sensibilização das crianças para o ritmo dos versos e revelam-se como bons modelos para treinar o processo de encadeamento das palavras no verso ou dos versos na estrofe. A estrutura simples e repetitiva possibilita que o modelo seja reproduzido, acrescentando-se novas cidades e as respetivas rimas.

Do mesmo modo, os trava ou destrava-línguas apresentam-se como atrativos jogos fonéticos e de linguagem que permitem a leitura em coro e atividades de produção escrita. Recorrendo à definição de Alexandre Parafita (1999, p. 87), estas composiçóes, oriundas do património oral, são "pequenos textos organizados 
do ponto de vista fónico e linguístico de modo a criarem obstáculos à articulação de consoantes e vogais, gerando dificuldades de pronúncia”.

Os exemplos que a seguir apresentamos foram retirados da seleção de Luísa Ducla Soares, Destrava Linguas, publicados pela primeira vez em 1997 e com 2a edição em 2006:

\author{
Tenho um colarinho \\ muito bem encolarinhado. \\ Foi o colarinhador \\ que me encolarinhou \\ este colarinho \\ Vê se és capaz \\ de encolarinhar \\ tão bem encolarinhado \\ como o encolarinhador \\ que me encolarinhou \\ este colarinho.
}

(SOARES, 2006, p. 28).

\author{
Esta burra torta trota \\ Trota, trota, a burra torta. \\ Trinca a murta, a murta brota \\ Brota a murta ao pé da porta. \\ (SOARES, 2006, p. 8).
}

Estes enunciados, com uma forte componente lúdica, possibilitam desenvolver a competência da expressáo oral, bem como o gosto e o prazer de ler, na medida em que, ao exigirem a exercitação das várias posiçóes do aparelho fonador (torta/trota/brota/porta/burra/murta), as dificuldades da sua rápida recitaçáo constituem um desafio aliciante para os mais novos. No primeiro exemplo, a palavra "colarinho" desdobra-se em "encolarinhar", "encolarinhador" e "encolarinhado", ou seja, verbo, substantivo e adjetivo, que, quase com a mesma pronúncia, obrigam a uma agilizada articulação das palavras.

Como destacaram Maria da Conceição Costa (1992) e Isabel Margarida Duarte (2002), entre outros investigadores, o domínio da respiração na articulação dos trava-línguas facilita a aprendizagem no domínio da respiração em leitura, ao mesmo tempo que torna mais facilmente observáveis certos sons com diferente realização gráfica. Estas estruturas linguísticas são, pois, didaticamente enriquecedoras nas salas de aula dos primeiros anos, tornando-se uma mais-valia na tomada de consciência dos vários órgáos do aparelho fonador na produção dos diversos sons (CABRAL, 2002).

A obra Linguas de Perguntador, de João Pedro Mésseder (2009), constitui um outro exemplo de como a literatura oral ainda vive nos textos de autores 
contemporâneos, embora atualizada em função da própria evolução do sistema literário. As perguntas são lançadas, como se de crianças proviessem, e as respostas constituem um desafio à imaginação de cada um. Apresentamos de seguida alguns dos melhores exemplos (MÉSSEDER, 2009):

- Há asnos inteligentes?

- Sim, mas só os que são

verdadeiros burros.

- Há serpentes no céu?

- Sim, cobras flamejantes

que pregam sustos

em noites de temporal

e por vezes mordem

(e muito)

quem se abriga

debaixo das árvores.

- Há palhaços sérios?

- Sim, são todos sérios de mais, mas fora da arena do circo.

- Há pessoas solitárias

entre as multidóes?

- Sim, muitas -

que assim sentem, mais ainda,

a solidão na companhia dos outros.

Embora lembrando a estrutura dialogística das cantigas populares, estas composiçóes apresentam-se atuais pelos conceitos, atitudes e posturas perante a vida que evocam página após página, deixando sempre espaço para uma reflexão e o convite a uma nova pergunta.

Com raízes na literatura de tradição oral, as adivinhas, os trava-línguas, as lengalengas, os diálogos e os refróes constituem relevantes textos que devem fazer parte de um currículo fundamentado na literatura. Se nos primeiros anos de escolaridade, eles surgem, em sala de aula, como motivação para a leitura da poesia, visando o acesso das crianças às estruturas mais simples aproximadas das poéticas, à medida que progredimos na escolaridade, eles podem constituir 
bons modelos para a compreensão e reprodução de textos da tradição oral, bem como relevantes momentos de interação lúdica entre alunos ou enquanto estratégias promotoras da intertextualidade.

\section{Libertação da linguagem e dos limites da língua}

Uma das características do discurso poético traduz-se na possibilidade de a linguagem jogar consigo própria e de ultrapassar os seus limites sem desrespeitar o código. Como observa Georges Jean (1995, p. 118), a "liberdade verbal [na poesia] é mais eficaz quando é controlada", pelo que o trabalho poético tem vindo cada vez mais a descobrir combinaçóes vocabulares possíveis no sistema, mas inéditas na norma. No desenvolvimento da competência literária, há diversas atividades que se podem realizar em contexto de sala de aula com um duplo objetivo: recusar associaçóes convencionais das palavras para, realçando a dimensão criadora do material verbal, permitir aos utilizadores da língua agir nela e através dela de uma forma mais eficaz ou produtiva.

Os neologismos constituem uma forma muito apreciada pelos poetas para enriquecerem a linguagem nos textos para a infância, nomeadamente os neologismos semânticos, como é o caso da metáfora. A formação e emprego de formas novas e inexistentes, mas possíveis na língua, não resultam aberrantes e não chocam o sentido linguístico de quem as recebe. Segundo Guilbert (1975), os neologismos de sentido ocorrem sem que nenhuma alteração se verifique ao nível do significante, valendo apenas quando inseridos numa frase e/ou num sintagma. Ao contrário dos neologismos lexicais, que são reconhecidos pela própria forma, os de sentido só no discurso adquirem significação.

A palavra-mala, ou mot-valise, corresponde ao termo portmanteau-word, teorizado por Lewis Carroll no século XIX, em Through the Looking Glass, como um significante novo onde estâo reunidos dois significantes, portadores de significados distintos (CARROLL, 1998). Neste tipo de redução vocabular, as duas bases são privadas de parte dos seus elementos para constituírem uma nova unidade lexical. Ora, este mecanismo desconstrutivo da linguagem tornase um desafio na turma, quando o professor sugere que cada um forme uma palavra-mala que terá de ser descodificada pelos colegas ou através de desenho ou por meio da expressão oral. 
Maria Helena Pires (2009), em Tretaletra, juntou as palavras "tricotando" e "contando" para formar uma nova palavra, no poema "Tricontando", que a seguir se apresenta:

\author{
Triconto \\ esta história \\ duma salta folhinhas \\ que, \\ num pé de página \\ se aninhou, \\ buscando segredos \\ que nunca contou... \\ $O$ retalho deste meu conto \\ que aqui conto \\ bem contado \\ está, \\ por isso, \\ inacabado. \\ Acaba-o tu. Obrigado.
}

O significado de "tricotar" cruza-se com o de "contar", formando um novo verbo, "tricontar", com uma aceção igualmente nova. "Tricontar" é muito mais do que simplesmente fazer tricô ou relatar detalhes de uma história. Deste processo resulta um vocábulo original, que corresponde à criação de uma só unidade significante e, consequentemente, de um novo significado e um novo referente. No exemplo proposto, "tricontar" pretende ser um verbo que significa contar uma história como se se tratasse de um tecido de malhas entrelaçadas ou episódios cruzados. O sujeito enunciador diz que vai tricontar a história de uma salta folhinhas (alusão à Saltapocinhas, a raposa do romance de Aquilino Ribeiro), mas entretanto deixa o conto inacabado e ordena ao leitor que o termine.

O título do poema de Alexandre O'Neill (2001, p. 416), A estouvaca, constitui um outro exemplo de mot-valise, feita com a junção das palavras "estouvada" e "vaca". A nova palavra, inexistente no dicionário, compreende um significado que ultrapassa o sentido de uma vaca estouvada, que se deita numa estrada e é imediatamente atropelada, ainda durante a enunciação do poema: 
A estouvaca

\author{
deitada atravessada \\ na estrada \\ a malhada \\ vai ser atropelada \\ foi
}

(O’NEILL, 2001, p. 416).

Repare-se que, ao contrário do que acontece com a metáfora, os significantes iniciais, antes do processo de junção, não partilham qualquer relaçấo analógica ao nível do conteúdo, necessária, no entanto, no plano dos significantes para que os vocábulos se cruzem e sejam morfologicamente admissíveis no sistema.

Para a iniciação do trabalho com este tipo de palavras, Perry (1997) propóe a seguinte atividade: o professor deve preparar uma lista com palavras compostas e explica o conceito à turma, dando exemplos no quadro. Pode aproveitar para diferenciar palavras compostas por justaposição ou por aglutinação das palavrasmala. A partir daqui, sugere que sejam os alunos a elaborarem uma lista de palavras, por exemplo no âmbito do estudo do meio, os animais, e arriscarem a invenção de palavras compostas, que posteriormente devem ser colocadas formando um poema.

Podem surgir palavras como "cabrodilo" (cabra + crocodilo) ou "abelhobra" (abelha + cobra). Antes de escreverem o poema, as crianças devem pensar nas características dos novos seres e podem também ser convidadas a fazer uma ilustração que ajude a descrever o novo animal inventado.

Jacqueline Held, num capítulo intitulado "Fantástico, Linguagem e Poesia", pertencente à sua obra mais conhecida, O imaginário no poder (HELD, 1980), sublinha a preferência infantil pelos jogos verbais que nascem muitas vezes do absurdo e do imprevisto. A autora fala de uma "liberdade profunda diante da palavra" (HELD, 1980, p. 197), numa fase em que a criança possui um prazer desligado da ideia preconcebida de comunicaçáo. Neste sentido, os jogos poéticos de forma e de linguagem constituem hipóteses de trabalho que não só facilitam o acesso à poesia como preparam os jovens leitores para um olhar mais atento sobre a constituiçáo do poema e seus aspetos formais, fonéticos, morfossintácticos e estilísticos. 


\section{Cruzando a poesia com outras formas de expressão}

O contacto com a poesia, embora passe pelo conhecimento das estruturas edificadoras, formais e linguísticas do próprio texto, promove a interação com áreas afins que prefiguram uma linguagem simbólica, como é o caso da pintura, da dramatização e da música.

Os melhores poemas terão sido escritos para serem declamados ou cantados, tal como acontece hoje em dia com muitos dos poemas destinados ao público infantil. Logo, uma das melhores formas de iniciar a poesia com as crianças é através da representação (BAGERT, apud CULLINAN, 1992), da música ou da pintura. Essa interdisciplinaridade é do agrado das crianças, que buscam nos poemas os sons, os movimentos, as imagens e a narração de uma história.

Ler um poema é igualmente ter uma visão simultânea da página (JEAN, 1995), tendo em atenção os espaços brancos do texto, a pontuação ou a distribuição estrófica. As rimas, a métrica, o ritmo, os acentos, os sons, os silêncios, as pausas, os sinais sobrepóem-se, enlaçam-se, cruzam-se, conduzindonos a uma leitura pela página, pela disposição gráfica, pelo conteúdo e pela forma. Perry (1997, p. 17) defende assim que "reading aloud is a critical moment of self-discovery and learning", na medida em que a experiência de leitura perante outros, o treino do controlo da respiração, o clima de respeito mútuo e o desenvolvimento da autoestima proporcionam a descoberta da própria voz e da voz dos outros.

Embora mais habituadas ao texto narrativo dentro e fora da escola, as crianças acabam por aderir espontaneamente ao poema pela sua reduzida dimensão, sonoridade e concentração temática. As rimas, a aliteração, o ritmo e a musicalidade seduzem os jovens leitores, que entendem a leitura da poesia como um desafio e procuram novas experiências a cada leitura que fazem. Por conseguinte, Georges Jean (1995) acredita que as crianças nos $2^{\circ}$ e $3^{\circ}$ anos do $1^{\circ}$ Ciclo do Ensino Básico leem melhor e mais depressa textos de poesia que lhe são propostos do que textos em prosa.

Cullinan, Scala e Schroder (1995) sublinham a importância de a criança saber reconhecer desde cedo o código poético para que possa fazer uma leitura em conformidade. A leitura da poesia com os olhos é uma das vias mais importantes para a aprendizagem da leitura. Observar um poema implica ver os ritmos dos vocábulos, dos espaços em branco, das quebras de verso, da 
expressividade das palavras. A declamação implica reinventar o poema, não reduzi-lo a decorar ou memorizar.

Além disso, como adverte Georges Jean (1995, p. 221), a "atividade poética passa obrigatoriamente pela escuta, pela leitura e pela escrita", escuta não só dos outros também de nós próprios, ainda que em silêncio. Se a criança está habituada a uma matriz rítmica desde o berço, o professor só terá de manter essa rotina, para que o contacto com o ritmo não se perca.

Se a função última do texto poético é interrogar, como afirma Teresa Guedes (1995), é necessário encontrar estratégias em sala de aula que, por um lado, facilitem o desbloqueio e, por outro, despertem a originalidade, tanto para a leitura como para a escrita do texto poético. Para tal, a autora (GUEDES, 1995) sugere o jogo da exploração das palavras "pontiagudas", entendidas como as palavras amadas (riacho, mãe, lua) que metem medo (tempestade, poço) ou que divertem (rir, beijoca), perante as quais é impossível ficar-se indiferente. Um outro jogo é a "caça aos lugares comuns", em que os alunos são treinados a evitar os lugares comuns de um determinado tema. O exemplo dado por Guedes (1995, p. 81) é esclarecedor: "Quando se fala de Outono, já todos sabemos que as folhas caem [...] e que fazem as vindimas. Mas o que não sabemos é que [...] aquela antena de televisão [...] abana desenfreadamente com o vento outonal".

Neste sentido, a atividade poética pode começar na sala de aula e estenderse ao imaginário, quando o professor utiliza com frequência estratégias como o do "Vamos Pensar", o "Canto da Poesia", a "Caixa de Ferramentas da Poesia" ou a "Casa da Poesia" (PERRY, 1997, p. 9), promovendo rotinas que definem um ambiente propício para o contacto com o texto poético. Aliás, as diversificadas sugestóes de Perry (1997) passam sempre pela atividade de escrita poética, já que uma das formas de manter determinada rotina em sala de aula é precisamente diversificando as estratégias e as metodologias de ensino-aprendizagem.

\section{Conclusões}

Ao longo deste artigo, sublinhámos a relevância das experiências positivas e dos contextos adequados para a adesão dos jovens leitores à leitura voluntária.

Assinalámos que trabalhar a poesia em contexto pedagógico pode constituir uma oportunidade para os jovens leitores conhecerem o rico património da sua cultura e literatura, bem como para experimentarem a 
plasticidade e a materialidade sonora da linguagem, tornando-a uma forma de ação que lhes possibilita agirem no mundo, ao permitir-lhes expressarem-se de um modo plural e integral. Os textos poéticos, presentificando uma visão inédita e singular do mundo, revelam-se pertinentemente úteis para permitir, aos jovens leitores, acederem a outros modos de dizer, de expressar e de pensar os mundos possíveis. Modos esses que, afigurando-se fertilizadores da sua competência enciclopédica, os auxiliam a situarem-se no mundo e a agir nele. De facto, ao interagirem com a poesia, os jovens leitores desenvolvem e consolidam competências linguísticas, cognitivas e estratégias de compreensão; familiarizamse com a linguagem conotativa e metafórica; expandem conhecimentos culturais, mergulhando no grande universo da sensibilidade e dos afetos.

\section{REFERÊNCIAS}

AZEVEDO, Fernando. Formar leitores capazes de ler o mundo desde uma idade precoce: os lugares da literatura infantil e juvenil na sociedade contemporânea. In: SILVA, João Amadeu; MARTINS, José Cândido; GONÇALVES, Miguel (Org.). Pensar a literatura no séc. XXI. Braga: Universidade Católica Portuguesa, 2011, p. 271-278.

BÁRTOLO, Vítor N. A motivação para a leitura. In: LOPES, João Arménio Lamego; VELASQUEZ, M. Gabriela; FERNANDES, Paulo; BÁRTOLO, Vítor N. Aprendizagem, ensino e dificuldades da leitura. Coimbra: Quarteto, 2004, p. 139-183.

BASTOS, Glória. Literatura infantil e juvenil. Lisboa: Universidade Aberta, 1999.

CABRAL, Maria Manuela. Como abordar... o texto poético. Porto: Areal Editores, 2002.

CARROLL, Lewis. Through the Looking Glass. London: Penguin, 1998.

CERRILLO, Pedro. Literatura infantil e mediação leitora. In: AZEVEDO, Fernando (Coord.). Lingua materna e literatura infantil: elementos nucleares para professores do ensino básico. Lisboa: Lidel, 2006, p. 33-46.

COSTA, Maria da Conceição. Um continente poético esquecido: as rimas infantis. Porto: Porto Editora, 1992. 
CULLINAN, Bernice E. Invitation to read: more children's literature in the reading program. Newark: International Reading Association, 1992.

CULLINAN, Bernice E. (Org.). La lectura en el aula: ideas y estrategias de enseñanza para la formación de lectores. México: Trillas, 2003.

CULLINAN, Bernice E.; SCALA, Marilyn C.; SCHRODER, Virginia C. Three voices: an invitation to poetry across the curriculum. Portland: Stenhouse Publishers, 1995.

CHATTON, Barbara. Using poetry across the curriculum: a whole language approach. Westport, CT: Greenwood Publishing Group - Oryx Press, 1993.

DUARTE, Isabel Margarida (Org.). Gavetas de leitura: estratégias e materiais para uma pedagogia da leitura. Porto: Asa, 2002.

FANHA, José (Org.). Poemas da natureza. Ilustração de Pedro Pires. Vila Nova de Gaia: Gailivro, 2005.

FERREIRA, Sandra Patrícia Ataíde; DIAS, Maria da Graça Bompastor Borges. A leitura, a produção de sentidos e o processo inferencial. Psicologia em Estudo, Maringá, v. 9, n. 3, p. 439-448, 2004.

FILLOLA, Antonio Mendoza. Los intertextos: del discurso a la recepción. In: FILLOLA, Antonio Mendoza; CERRILLO, Pedro C. (Coord.).

Intertextos: aspectos sobre la recepción del discurso artístico. Cuenca: Ediciones de la Universidad de Castilla-La Mancha, 2003, p. 17-60.

FREIRE, Paulo. Reading the word and the world. South Hadley: Bergin \& Garvery, 1987.

FRYE, Northrop. The well-tempered critic. Bloomington: Indiana University Press, 1963.

GUEDES, Teresa. Ensinar a poesia. Porto: Edições Asa, 1995.

GUILBERT, Louis. La créativité lexicale. Paris: Larousse, 1975.

GUTHRIE, John T.; MCCANN, Ann Dacey. Characteristics of classrooms that promote motivations and strategies for learning. In: GUTHRIE, John T.; WIGFIELD, Allan (Eds.). Reading engagement: Motivating readers through integrated instruction. Newark: International Reading Association, 1997, p. 128-148. 
HELD, Jacqueline. $O$ imaginário no poder: as crianças e a literatura fantástica. São Paulo: Sumus, 1980.

JEAN, Georges. Na escola da poesia. Lisboa: Piaget, 1995.

MARCUSCHI, Luiz António. Leitura como um processo inferencial num universo cultural-cognitivo. Leitura: teoria e prática. Campinas, Associação de Leitura do Brasil, p. 3-16, 1985.

MARINA, José Antonio; VÁLGOMA, María de la. A magia de ler. Lisboa: Âmbar, 2007.

MARTÍN, Fernando E. Gómez. Didáctica de la poesía en la educación infantil y primaria: Guía práctica para la enseñanza de la lírica en los niños. Madrid: Editorial Cincel, 1993.

MÉSSEDER, João Pedro. Línguas de Perguntador. Ilustração de Madalena Matoso. Prior Velho: Paulinas Editora, 2009.

MOTA, António. Se tu visses o que eu vi. Ilustração de Elsa Navarro. Vila Nova de Gaia: Gailivro, 2002.

O’NEILL, Alexandre. Poesias completas. Lisboa: Assírio \& Alvim, 2001.

PARAFITA, Alexandre. A comunicação e a literatura popular. Lisboa: Plátano Editora, 1999.

PERRY, Aaren Yeatts. Poetry across the curriculum: an action guide for elementary teachers. Needham Heights: Allyn \& Bacon, 1997.

PIRES, Maria Helena. Tretaletra. Ilustração de Elisabete Ferreira. Porto: Trinta por uma linha, 2009.

SEDGWICK, Fred. Writing to learn: poetry and literacy across the primary curriculum. New York: Routledge Falmer, 2000.

SLOAN, Glenna Davis. The child as critic: teaching literature in elementary and middle schools. New York-London: Teachers College Press/Columbia University, 1991.

SOARES, Luísa Ducla. Destrava Linguas. Ilustração de Susana Oliveira. Lisboa: Livros Horizonte, 2006.

SOLÉ, Isabel. Estrategias de lectura. Barcelona: Universitat de Barcelona Institut de Ciències de Educació, 2000. 
SPINILLO, Alina Galvão; MAHON, Érika da Rocha. Compreensão de texto em crianças: comparaçóes entre diferentes classes de inferência a partir de uma metodologia on-line. Psicologia: Reflexão e Crítica, Porto Alegre, v. 20, n. 3, p. 463-471, 2007. Disponível em: <http://www.scielo.br/scielo. php? script $=$ sci_arttext\&pid=S0102-79722007000300014\&lng=en\&nrm=i so>. Acesso em: 6 mar. 2012.

YOPP, Hallie K.; YOPP, Ruth. Literature-based reading activities. 4. ed. Boston: Pearson, 2006. 


\section{Poesía infantil e formación Poetry in childhood and the lectora education of readers}

\section{Resumen}

Este texto presenta un conjunto de estrategias para leer y apreciar la poesía en el contexto de la escuela, en los primeros ańos. Se entiende que la poesía es un tipo de texto adonde la elevada concentranción sígnica y la multivalencia semántica, expandidas por la plurisignificación del conjunto de elementos del contenido conjugados con los de la expresión, posibilita, al lector, el contacto emocional y afectivo con el estado de cosas del mundo empírico e histórico-factual, sugiriendo caminos hermenéuticos plurales para su acceso, conocimiento y reflexión. Se defiende que el fruir del texto poético es relevante para la creación de hábitos lectores, aspecto crucial para la formación de lectores que leen voluntariamente en cuantidad e con cualidad.

Palabras claves: Literatura infantil. Lectura. Didáctica.

\begin{abstract}
This article presents strategies for reading and appreciating poetry in schools, particularly in the early elementary grades. Poetry is conceived as a type of text where the high concentration of symbolism and the semantic multi-valence, expanded by the plural signification of the conjugation of the elements of content with those of expression, allow the reader to have emotional contact with the state of things from the empiric and historic-factual world, suggesting plural hermeneutic paths to their access, knowledge and reflection. The paper understands that the fruition of the poetic text is important in the creation of readers' habits, an essential factor for the formation of readers who are capable of reading voluntarily in quantity and quality.
\end{abstract}

Keywords: Children's literature. Reading. Didactics. 
Fernando José Fraga de Azevedo

E-mail:fraga@ie.uminho.pt

Isabel Souto e Melo

E-mail: ismelo.isce@gmail.com

Recebido em: 13/3/2012

Versáo final recebida em: $16 / 11 / 2012$

Aprovado em: 26/11/2012

PERSPECTIVA, Florianópolis, v. 30, n. 3, 925-946, set./dez. 2012

http://www.perspectiva.ufsc.br 